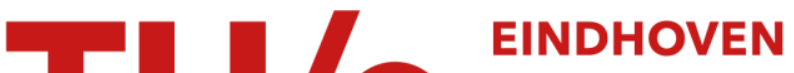 UNIVERSITY OF TECHNOLOGY
}

\section{Real-time demonstration of ARoF fronthaul for high-bandwidth mm-Wave 5G NR signal transmission over multi-core fiber}

\section{Citation for published version (APA):}

Rommel, S., Cimoli, B., Grivas, E., Dodane, D., Morales, A., Pikasis, E., Bourderionnet, J., Feugnet, G., Barros Carvalho, J., Katsikis, M., Ntontin, K., Kritharidis, D., Spaleniak, I., Mitchell, P., Dubov, M., \& Monroy, I. T. (2020). Real-time demonstration of ARoF fronthaul for high-bandwidth mm-Wave 5G NR signal transmission over multi-core fiber. In 2020 European Conference on Networks and Communications, EuCNC 2020 (pp. 205208). [9200921] Institute of Electrical and Electronics Engineers.

https://doi.org/10.1109/EuCNC48522.2020.9200921

DOI:

10.1109/EuCNC48522.2020.9200921

Document status and date:

Published: 01/06/2020

\section{Document Version:}

Accepted manuscript including changes made at the peer-review stage

\section{Please check the document version of this publication:}

- A submitted manuscript is the version of the article upon submission and before peer-review. There can be important differences between the submitted version and the official published version of record. People interested in the research are advised to contact the author for the final version of the publication, or visit the $\mathrm{DOI}$ to the publisher's website.

- The final author version and the galley proof are versions of the publication after peer review.

- The final published version features the final layout of the paper including the volume, issue and page numbers.

Link to publication

\section{General rights}

Copyright and moral rights for the publications made accessible in the public portal are retained by the authors and/or other copyright owners and it is a condition of accessing publications that users recognise and abide by the legal requirements associated with these rights.

- Users may download and print one copy of any publication from the public portal for the purpose of private study or research.

- You may not further distribute the material or use it for any profit-making activity or commercial gain

- You may freely distribute the URL identifying the publication in the public portal.

If the publication is distributed under the terms of Article 25fa of the Dutch Copyright Act, indicated by the "Taverne" license above, please follow below link for the End User Agreement:

www.tue.nl/taverne

Take down policy

If you believe that this document breaches copyright please contact us at:

openaccess@tue.nl

providing details and we will investigate your claim. 


\title{
Real-Time Demonstration of ARoF Fronthaul for High-Bandwidth mm-Wave 5G NR Signal Transmission over Multi-Core Fiber
}

\author{
Simon Rommel*ף ${ }^{\star}$ Bruno Cimoli*, Evangelos Grivas ${ }^{\dagger}$, Delphin Dodane ${ }^{\ddagger}$, Alvaro Morales*, Evangelos Pikasis ${ }^{\dagger}$, \\ Jerome Bourderionnet $^{\ddagger}$, Gilles Feugnet ${ }^{\ddagger}$, Juliana Barros Carvalho*, Michail Katsikis ${ }^{\S}$, Konstantinos Ntontin ${ }^{\S}$, \\ Dimitrios Kritharidis ${ }^{\S}$, Izabela Spaleniak", Paul Mitchell", Mykhaylo Dubov", and Idelfonso Tafur Monroy* \\ ${ }^{*}$ Institute for Photonic Integration, Eindhoven University of Technology, 5600MB Eindhoven, Netherlands \\ ${ }^{\dagger}$ Eulambia Advanced Technologies, 15342 Agia Paraskevi, Athens, Greece \\ ${ }^{\ddagger}$ Thales Research \& Technology, Route Départementale, 91120 Palaiseau, France \\ $\S$ Intracom Telecom, Markopoulou Avenue, 19002 Peania, Athens, Greece \\ ॥ Optoscribe, Unit 1, Rosebank Technology Park, Livingston EH54 7EJ, United Kingdom \\ Is.rommel@tue.nl
}

\begin{abstract}
This paper presents an experimental demonstration of analog radio-over-fiber (ARoF) fronthaul for high-bandwidth, high-capacity millimeter wave (mm-wave) extended fifth generation mobile network (5G) new radio (NR) signals over an optical distribution network with optical space division multiplexing (SDM). AROF is shown to alleviate fronthaul capacity bottlenecks, transporting an $800 \mathrm{MHz}$ wide extended 5G NR signal and allowing to maintain full centralization in a centralized radio access network (C-RAN). The proposed AROF fronthaul architecture features a transmitter that generates the AROF signal and an optical signal carrying a reference local oscillator (LO) employed for downconversion at the remote unit (RU) from a single radio frequency ( $\mathrm{RF})$ reference at the central office ( $\mathrm{CO}$ ). An SDM based RAN with 7-core multi-core fiber (MCF) allows parallel transport of the uplink AROF signal and reference LO at the same wavelength over separate cores. Transmission of an $800 \mathrm{MHz}$ wide extended $5 \mathrm{G}$ NR fronthaul signal over 7core MCF is shown with full real-time processing, achieving $1.4 \mathrm{Gbit} / \mathrm{s}$ with $\mathrm{BER}<3.8 \times 10^{-3}$ and thus below the limit for hard-decision forward error correction (FEC) with $7 \%$ overhead. Downconversion at the $\mathrm{RU}$ is performed electrically with the remote-fed LO provided by the co.
\end{abstract}

Keywords-5G, millimeter wave, space division multiplexing, analog radio-over-fiber, fronthaul.

\section{INTRODUCTION}

As the demand for mobile data continues to increase and the range of applications expands, fifth generation mobile networks (5Gs) promise unprecedented data rates, low latency and support of extreme user densities [1], [2]. For the first time for mobile networks, $5 \mathrm{G}$ new radio (NR) includes the use of millimeter wave (mm-wave) carrier frequencies to allow the use of larger signal bandwidths and thus achieve the required Gbit/s end-user capacities [2]-[4]. Centralized radio access networks (C-RANs) have been shown to provide significant gains in terms of CAPEX and OPEX by centralizing network functionality and complexity at the central office (CO) and reducing footprint and energy consumption of the remote unit (RU) [5], [6]. The resulting introduction of the fronthaul segment, which transports the radio waveforms between $\mathrm{CO}$ and RU in digitized form over optical fiber, however poses stringent requirements on latency and, due to high-resolution digitization, requires large data-rates even for small radio frequency (RF) bandwidths [7], [8]. With signals above $100 \mathrm{MHz}$ bandwidth to be used in $5 \mathrm{G}$ NR, traditional digitized radioover-fiber (DROF) fronthaul based on CPRI can not cope and analog radio-over-fiber (AROF) fronthaul becomes the only option to maintain full centralization and avoid an - at least partial - return to a distributed RAN [9], while also minimizing the required optical bandwidth.

In addition to ARoF, space division multiplexing (SDM) in the optical domain can help alleviating the capacity concerns of 5G C-RANs, providing multiple independent parallel paths at a potentially lower cost point than wavelength division multiplexing (WDM) or in combination with the latter to further increase capacity [10]-[13]. SDM may further help in avoiding differential delays or different chromatic dispersion experienced by related signals, or by allowing simultaneous transport of signals at identical wavelength within the same fiber [9], [14], [15].

In this work, an ARoF over multi-core fiber (MCF) link is demonstrated with full real-time processing of the AROF signal in a custom AROF baseband unit (BBU) and intermediate frequency (IF) transport over $10 \mathrm{~km}$ of 7-core MCF. Optical and $9 \mathrm{~m}$ wireless transmission at $25.5 \mathrm{GHz}$ of an $800 \mathrm{MHz}$ wide extended $5 \mathrm{G}$ NR signal, compliant with 3GPP orthogonal frequency division multiplexing (OFDM) numerology [16], are shown, achieving a data rate of $1.4 \mathrm{Gbit} / \mathrm{s}$ and bit error rates (BERs) below $3.8 \times 10^{-3}$. Optical two-tone generation based on an Mach-Zehnder modulator (MZM) and optical heterodyning are employed for upconversion to mm-wave, while an unmodulated copy of the two tone signal, transported through the MCF, provides the LO for RF downconversion at the RU. The demonstrated ARoF fronthaul link thus achieves centralization of all frequency references, analog IFoF transport with optical heterodyning for mm-wave upconversion as well 


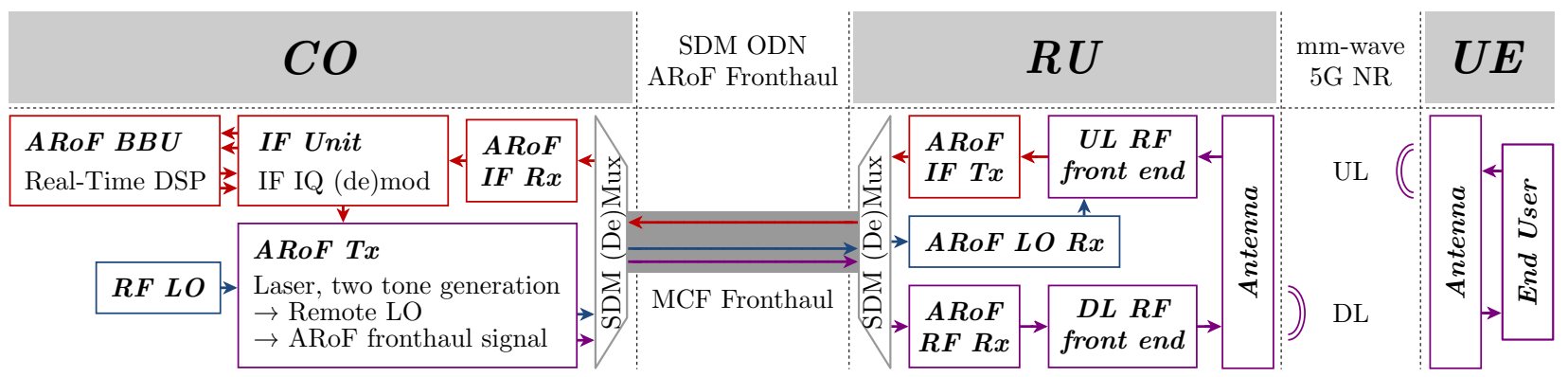

Fig. 1. Fronthaul architecture with CO, ARoF fronthaul over SDM based ODN, RU and mm-wave 5G NR air interface to the end user.

as - to the best of the authors' knowledge for the first time full real-time processing of an $800 \mathrm{MHz}$ ARoF extended 5G NR signal after wireless transmission at $25.5 \mathrm{GHz}$.

\section{Fronthaul Architecture And ExPerimental SETUP}

The proposed fronthaul architecture is shown in Fig. 1, outlining the CO, the SDM ODN with MCF, the RU, as well as the mm-wave $5 \mathrm{G} \mathrm{NR}$ air interface and end user (UE). At the $\mathrm{CO}$, the processing is performed at the AROF BBU, including analog-to-digital conversion for the downlink as well as digitalto-analog conversion for the uplink. The analog baseband IQ signals are fed to the IF unit for modulation onto the IF carrier, which in turn drives the AROF transmitter. The latter further receives an RF LO, used for two tone generation both for remote-feeding the LO and for the downlink AROF fronthaul signal. The signals are multiplexed for transmission over the SDM-based ODN for transport to the RU, where they are received by corresponding AROF receivers, performing optical heterodyne upconversion to mm-wave. The signal is amplified by the downlink RF front end and radiated towards the UE over the mm-wave 5G NR air interface. In the uplink direction the signal received form the $\mathrm{UE}$ at the RU is amplified by the uplink RF front end and downconverted using the remote-fed LO. The IF signal is transported over an IF AROF link over the same SDM-based ODN to the CO, where it is received by an
IF AROF receiver and fed to the IF unit for downconversion to baseband IQ signals.

The experimental setup employed to validate the AROF fronthaul link with real-time digital signal processing (DSP) is shown in detail in Fig. 2. The real-time AROF BBU generates a 5G NR signal with a total of 4096 subcarriers, spaced at $240 \mathrm{kHz}$, of which 3136 are active, resulting in an effective signal bandwidth of $760.32 \mathrm{MHz}$. The chosen modulation for the subcarriers is quadrature phase-shift keying (QPSK). The BBU further includes a digital to analog converter (DAC) and analog to digital converter (ADC) generating and receiving separate I and Q baseband signals respectively. Translation between baseband and IF is performed by the IF unit, employing a single IF LO at $f_{I F, L O}=5 \mathrm{GHz}$ and a pair of IQ-modulator and -demodulator.

Optical two-tone generation is performed by an MZM biased at the null point driven with an $\mathrm{RF} / 2 \mathrm{LO}$ at $f_{R F / 2, L O}=$ $10.25 \mathrm{GHz}$, resulting in a spacing of $20.5 \mathrm{GHz}$ between the two optical tones [17]. The two-tone signal is amplified and split in two equal branches, one directly transmitted via the MCF to the RU, where, after amplification by $30 \mathrm{~dB}$, it serves as RF LO at $f_{R F, L O}=20.5 \mathrm{GHz}$ for electrical downconversion of the uplink signal. The other copy of the two-tone signal is modulated with the IF signal from the IF unit in a second MZM, before being transmitted to the RU via a separate core of the

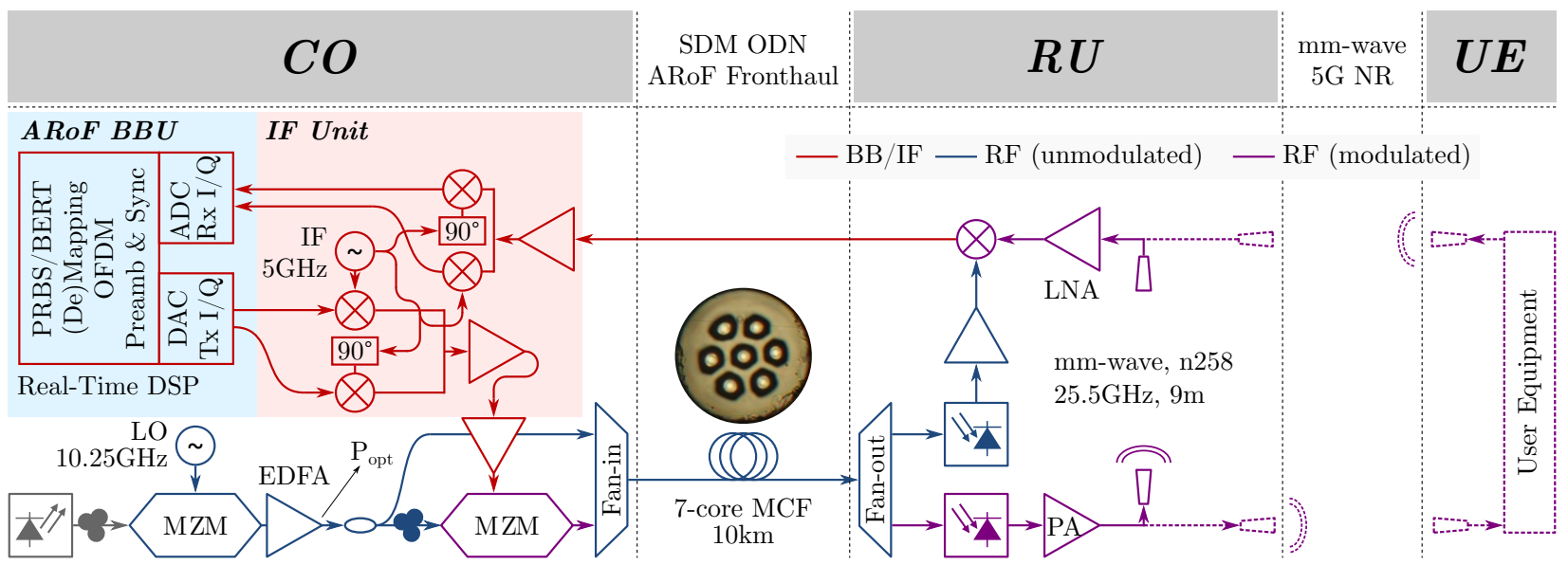

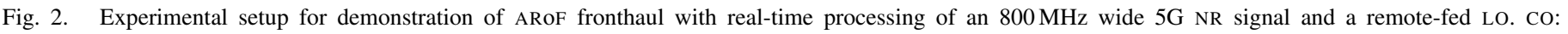

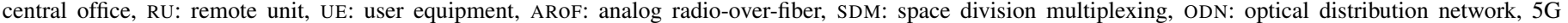

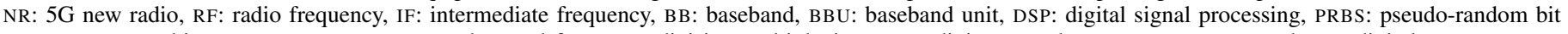

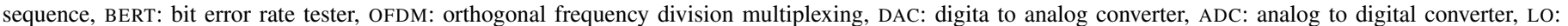
local oscillator, MZM: Mach-Zehnder modulator, EDFA: erbium doped fiber amplifier, MCF: multi-core fiber, PA: power amplifier, LNA: low noise amplifier. 

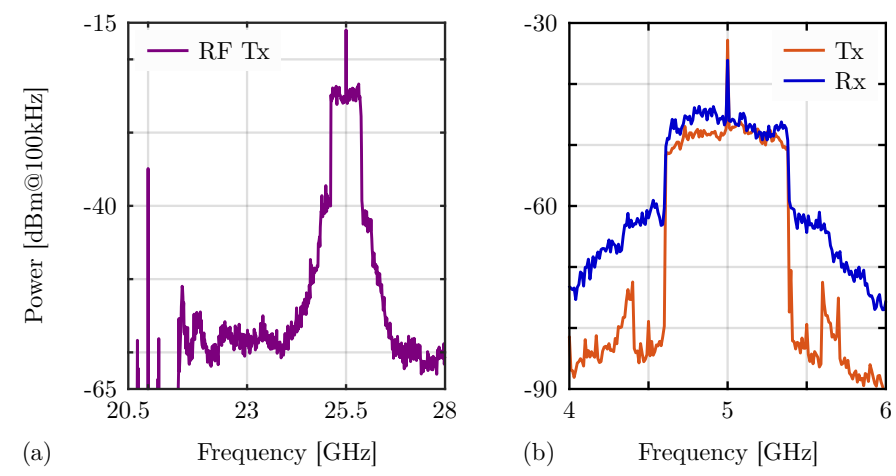

Fig. 3. Observed spectra at (a) RF transmission and (b) IF generation and reception.

$10 \mathrm{~km}$ 7-core MCF; here the use of MCF allows the seamless transport of both signals, despite being at the same wavelength.

At the RU, the downlink RF signal is generated by optical heterodyning of the modulated two-tone signal on the photodiode (PD), resulting in a signal that includes modulated components at $f_{R F, l o w}=f_{R F, L O}-f_{I F}$ and at $f_{R F}=$ $f_{R F, L O}+f_{I F}=25.5 \mathrm{GHz}$, as well as lower frequency components. The latter as well as the unwanted signal at $f_{R F, \text { low }}$ are removed by a high-pass filter, before the signal is amplified by $30 \mathrm{~dB}$ using a power amplifier (PA) and wirelessly transmitted at $25.5 \mathrm{GHz}$ - i.e., in the 3GPP n258 band [16] - over $9 \mathrm{~m}$. Wireless transmission is performed using a pair of horn antennas with a gain of $18.5 \mathrm{dBi}$ each. The received signal is amplified by $40 \mathrm{~dB}$ with an low-noise amplifier (LNA) before being downconverted to IF and fed back to the IF unit. Finally, the baseband IQ signals are returned to the AROF BBU for OFDM decoding and demodulation, as well as real-time BER evaluation.

It should be noted that for experimental convenience and to emulate a realistic worst case scenario, no end user is included and the transmitted signal of the RU is also its received signal. As the end-user is expected to perform electrical up- and downconversion for both up- and downlink, the demonstrated link is assumed to constitute a worst case in terms of phase and amplitude noise, as both the RF signal and the LO for downconversion are generated by optical heterodyning after MCF transmission and thus required significant amplification.

\section{EXPERIMENTAL RESULTS}

The evaluation of the presented ARoF fronthaul system is based on observation of the spectra of the transmitted RF signal and the transmitted and received IF signals (Fig. 3(a) and (b), respectively), as well as on the real-time BER calculated by the AROF BBU and corresponding signal constellations (Fig. 4(a) and (b), respectively). Figure 3(a) shows the transmitted RF spectrum, clearly showing the targeted $25.5 \mathrm{GHz}$ signal, as well as a tone at $f_{R F, L O}$ resulting from the beating of the two optical tones. The latter is suppressed by around $20 \mathrm{~dB}$ compared to the target carrier by the high-pass filter and as it is outside the antenna band it is not transmitted. Figure 3(b) shows a comparison of the transmitted and received IF signals centered at $5 \mathrm{GHz}$. While both signals have approximately equal power, the received IF signal has a severely degraded signal-to-noise ratio (SNR) of around $12 \mathrm{~dB}$, compared to

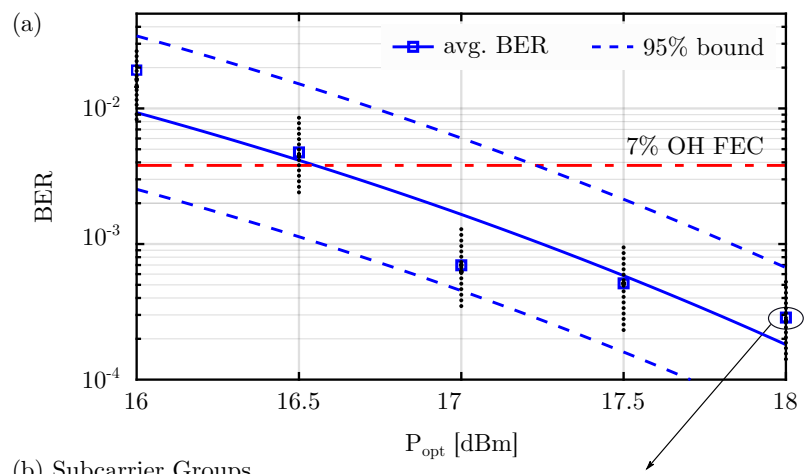

(b) Subcarrier Groups

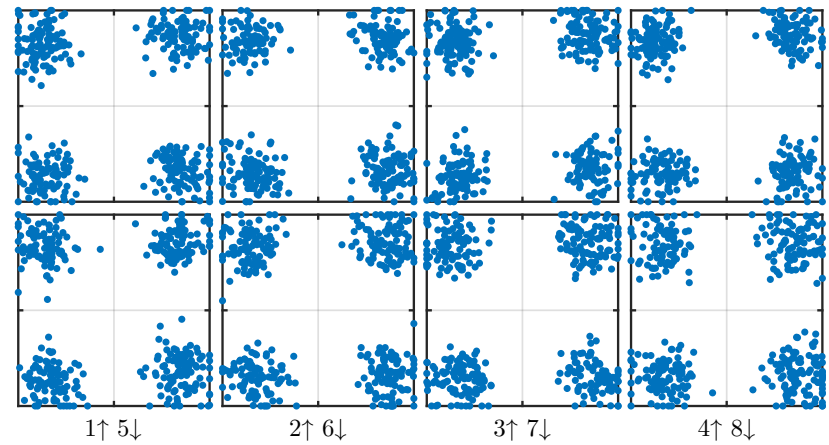

Fig. 4. Experimental results showing (a) the observed real-time BER over optical power and (b) the observed constellations.

$>30 \mathrm{~dB}$ for the transmitted IF signal. The received IF spectrum further has a slightly lower carrier-to-signal ratio as well as a tilt towards the higher frequencies, suggesting a non-flat system response across the IF spectrum.

System BER performance was evaluated for different optical powers after two-tone generation and hence for the case where both RF signal and LO vary in power as optical power varies. Thus, every $1 \mathrm{~dB}$ of optical power reduction translates directly into $2 \mathrm{~dB}$ of $\mathrm{RF}$ and $\mathrm{LO}$ power reduction and thus an estimated $5 \mathrm{~dB}$ in received IF power degradation - where the additional $1 \mathrm{~dB}$ is due to lower mixer efficiency at lower LO levels. BER is measured repeatedly over short time intervals of a few seconds at each power level, to not only capture average BER, but also its variation over time. The resulting BER measurements as well as their averages are shown in Fig. 4(a), alongside the BER limit for a standard forward error correction (FEC) with $7 \%$ overhead. The figure further shows the $95 \%$ confidence bounds for the BER for any such short time interval, derived from the measured BER statistics.

Finally, Fig. 4(b) shows the received constellations, splitting the $800 \mathrm{MHz}$ wide signals into eight subcarrier groups of equal width, i.e., roughly $100 \mathrm{MHz}$ wide. As can be seen, the constellations are similar for all groups, with mainly the first and the two last groups exhibiting some degradation. This can be attributed to a reduced low-frequency performance of the modulator in the IF unit as well as bandwidth limitations of the latter and the slight power reduction at higher frequencies previously observed on the received IF signal.

The observed BER performance and constellations shows that the presented AROF fronthaul and mm-wave transmission link can easily reach the BER limit for a simple hard-decision FEC with some power margin. This suggests operation at lower 
powers or with higher order constellations - and thus increased capacity - to be viable when including more complex coding schemes such as the ones usually employed in mobile and radio communications.

\section{CONCLUSIONS}

An ARoF fronthaul link with full real-time signal processing of an $800 \mathrm{MHz}$ wide extended 5G NR OFDM signal and IFoF transmission over $10 \mathrm{~km} 7$-core MCF was shown, achieving data rates of $1.4 \mathrm{Gbit} / \mathrm{s}$ after $9 \mathrm{~m} \mathrm{~mm}$-wave wireless transmission at $25.5 \mathrm{GHz}$ with BER below the $7 \%$ overhead FEC limit. The proposed ARoF fronthaul link further employs a remote-fed LO for electrical downconversion, thus achieving not only minimum optical bandwidth requirements through the use of IFoF, but also maximum centralization of network functionality and complexity.

The demonstrated fronthaul link validates the ARoF fronthaul concept and shows a possible use and advantage of SDM in the RAN. In addition, through the use of fully real-time signal processing, the potential for timely deployment of such links for mm-wave and high-capacity $5 \mathrm{G}$ is shown.

\section{ACKNOWLEDGMENTS}

This work was partially funded by the blueSPACE project (GA no. 762055) which has received funding from the European Union's Horizon2020 research and innovation programme.

\section{REFERENCES}

[1] E. Dahlman et al., "5G wireless access: Requirements and realization," IEEE Commun. Mag., vol. 52, no. 12, pp. 42-47, 2014.

[2] J. G. Andrews et al., "What will 5G be?" IEEE J. Sel. Areas Commun., vol. 32, no. 6, pp. 1065-1082, Jun. 2014.

[3] M. Xiao et al., "Millimeter wave communications for future mobile networks," IEEE J. Sel. Areas Commun., vol. 35, no. 9, pp. 1909-1935, Sep. 2017.
[4] Y. Tian, K. Lee, C. Lim, and A. Nirmalathas, " $60 \mathrm{GHz}$ analog radioover-fiber fronthaul investigations," J. Lightw. Technol., vol. 35, no. 19, pp. 4304-4310, Oct. 2017.

[5] A. Checko et al., "Cloud RAN for mobile networks-a technology overview," IEEE Commun. Surveys Tuts., vol. 17, no. 1, pp. 405-426, 2015.

[6] P. Rost et al., "Mobile network architecture evolution toward 5G," IEEE Commun. Mag., vol. 54, no. 5, pp. 84-91, May 2016.

[7] T. Pfeiffer, "Next generation mobile fronthaul and midhaul architectures," J. Opt. Commun. Netw., vol. 7, no. 11, pp. B38-B45, Sep. 2015.

[8] S. Rommel, T. R. Raddo, and I. Tafur Monroy, "The fronthaul infrastructure of 5G mobile networks," in Proc. IEEE Intl. Workshop Computer-Aided Modeling Analysis and Design of Communication Links and Networks (CAMAD). Barcelona, Spain: IEEE, Sep. 2018, paper S4.4.

[9] S. Rommel et al., "High-capacity 5G fronthaul networks based on optical space division multiplexing," IEEE Trans. Broadcasting, vol. 65, no. 2, pp. 434-443, Jun. 2019.

[10] Y. Liu, H. Yuan, A. Peters, and G. Zervas, "Comparison of SDM and WDM on direct and indirect optical data center networks," in European Conference on Optical Communication, 2016, pp. 76-78.

[11] A. Macho, M. Morant, and R. Llorente, "Next-generation optical fronthaul systems using multicore fiber media," J. Lightw. Technol., vol. 34, no. 20, pp. 4819-4827, Oct. 2016.

[12] J. M. Galve, I. Gasulla, S. Sales, and J. Capmany, "Reconfigurable radio access networks using multicore fibers," IEEE J. Quantum Electron., vol. 52, no. 1, p. 0600507, Jan. 2016.

[13] J. Brenes et al., "Network slicing architecture for SDM and analogradio-over-fiber-based 5G fronthaul networks," J. Opt. Commun. Netw., vol. 12, no. 4, pp. B33-B43, Apr. 2020.

[14] D. Konstantinou et al., "5G RAN architecture based on analog radioover-fiber fronthaul over UDWDM-PON and phased array fed reflector antennas," Opt. Commun., vol. 454, p. 124464, Jan. 2020.

[15] blueSPACE Consortium, "Space division multiplexing 5G fronthaul with analog and digital radio-over-fiber and optical beamforming - the blueSPACE concept," Aug. 2018. [Online]. Available: https: //doi.org/10.5281/zenodo.1403140

[16] 3GPP TS 38.104, "NR: Base station (BS) radio transmission and reception," Mar. 2018, 3GPP Rel. 15.

[17] S. Rommel et al., "W-band photonic-wireless link with a Schottky diode envelope detector and bend insensitive fiber," Opt. Express, vol. 24, no. 11, pp. 11312-11322, May 2016. 